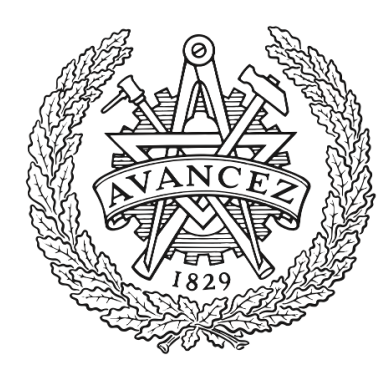

\title{
CHALMERS
}

UNIVERSITY OF TECHNOLOGY

\section{Cost-effective implementation of the Paris Agreement using flexible greenhouse gas metrics}

Downloaded from: https://research.chalmers.se, 2023-04-26 13:02 UTC

Citation for the original published paper (version of record):

Tanaka, K., Boucher, O., Ciais, P. et al (2021). Cost-effective implementation of the Paris Agreement using flexible greenhouse gas metrics. Science advances, 7(22).

http://dx.doi.org/10.1126/sciadv.abf9020

N.B. When citing this work, cite the original published paper. 


\section{Cost-effective implementation of the Paris Agreement using flexible greenhouse gas metrics}

\author{
Katsumasa Tanaka ${ }^{1,2,3 *}$, Olivier Boucher ${ }^{2}$, Philippe Ciais ${ }^{1}$, \\ Daniel J. A. Johansson ${ }^{4}$, Johannes Morfeldt ${ }^{4}$
}

Greenhouse gas (GHG) metrics, that is, conversion factors to evaluate the emissions of non- $\mathrm{CO}_{2} \mathrm{GHGs}_{\text {on a com- }}$ mon scale with $\mathrm{CO}_{2}$, serve crucial functions in the implementation of the Paris Agreement. While different metrics have been proposed, their economic cost-effectiveness has not been investigated under a range of pathways, including those substantially overshooting the temperature targets. Here, we show that cost-effective metrics for methane that minimize the overall mitigation costs are time-dependent, primarily determined by the pathway, and strongly influenced by temperature overshoot. Parties to the Paris Agreement have already adopted the conventional GWP100 (100-year global warming potential), which is shown to be a good approximation of cost-effective metrics for the coming decades. In the longer term, however, we suggest that parties consider adapting the choice of common metrics to the future pathway as it unfolds, as part of the recurring global stocktake, if global cost-effectiveness is a key consideration.
Copyright ๑ 2021

The Authors, some rights reserved; exclusive licensee American Association for the Advancement of Science. No claim to original U.S. Government Works. Distributed under a Creative Commons Attribution NonCommercial License 4.0 (CC BY-NC).

\section{INTRODUCTION}

Aligning climate policies with the goals of the Paris Agreement implies revisiting the concept of greenhouse gas (GHG) metrics. Emission metrics offer a simple way to quantify the combined climate impacts from the emissions of a mix of radiatively active gases and aerosols, without requiring a model. Specifically, a metric serves as an exchange index to convert the emission of a non- $\mathrm{CO}_{2}$ climate forcer to a so-called " $\mathrm{CO}_{2}$-equivalent emission" for climate policy purposes (Fig. 1). Emission metrics have, however, been a subject of debate and evaluation $(1,2)$ since the inception of $\operatorname{GWP}(3,4)$ in 1990. GWP100 (100-year global warming potential), the most widely used metric today, equates the emissions of different climate forcers with respect to the radiative forcing integrated over 100 years after a pulse emission (2). The consistency of GWP100 with policy goals has been questioned from physical and economic perspectives, and many alternatives have been proposed (5-15). The choice of metrics also reflects the priority for issues of concern $(16,17)$, influencing particularly how much the emissions of $\mathrm{CH}_{4}$, a shortlived climate forcer (SLCF) and currently the second most important source of radiative forcing after $\mathrm{CO}_{2}(2)$, should be reduced relative to those of $\mathrm{CO}_{2}$, which is of considerable importance in high $\mathrm{CH}_{4}$ emitting countries (fig. S1). While the scientific debate on metrics continues $(18,19)$, GWP100 has been adopted as the common metrics for the Paris Agreement implementation (20). Adopting common metrics for all parties to the Paris Agreement was a vital advance in the development of the so-called Paris Rulebook because it will enable cross-party comparisons of progress toward respective nationally determined contributions (NDCs), allow assessing the effect of specific mitigation actions and policies put in place, and permit

\footnotetext{
'Laboratoire des Sciences du Climat et de I'Environnement (LSCE), Institut Pierre-Simon Laplace (IPSL), Commissariat à l'énergie atomique et aux énergies alternatives (CEA)/Centre national de la recherche scientifique (CNRS)/Université de Versailles Saint-Quentin-en-Yvelines (UVSQ), Université Paris-Saclay, Gif-sur-Yvette, France. ${ }^{2}$ IPSL, CNRS/Sorbonne Université, Paris, France. ${ }^{3}$ Earth System Risk Analysis Section, Earth System Division, National Institute for Environmental Studies (NIES), Tsukuba, Japan. ${ }^{4}$ Division of Physical Resource Theory, Department of Space, Earth, and Environment, Chalmers University of Technology, Gothenburg, Sweden.

${ }^{*}$ Corresponding author. Email: katsumasa.tanaka@Isce.ipsl.fr
}

trading of credits between parties. However, it is unclear how costly this decision will be if GWP100 is the metric that will be permanently used for future mitigation strategies.

Here, we evaluate the use of GWP100 and other emission metrics in climate mitigation strategies on the basis of their cost-effectiveness in reference to the Paris Agreement temperature targets. The costeffectiveness is one of the key principles of the United Nations Framework Convention on Climate Change (UNFCCC) [Article 3 of (21)], as well as a guiding principle for climate mitigation pathways presented in the previous Intergovernmental Panel on Climate Change (IPCC) Assessment Reports. We use a simple globally

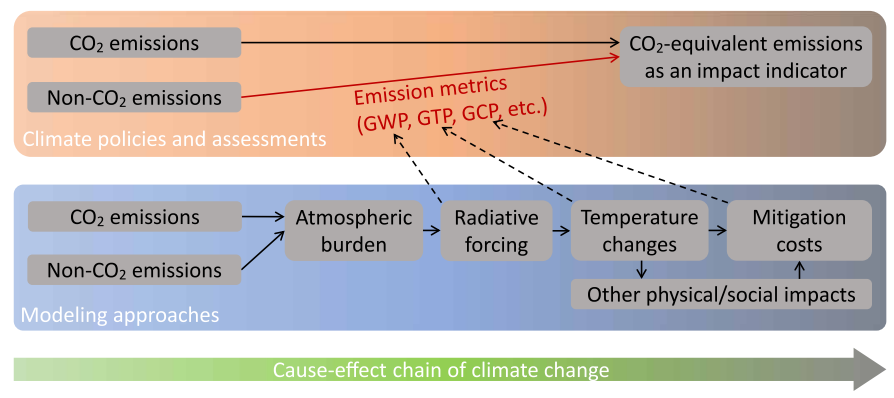

Fig. 1. The use of greenhouse gas emission metrics in climate policies and assessments and its relations to modeling approaches. The figure shows our interpretation that climate policies and assessments (orange-to-gray area) regard $\mathrm{CO}_{2}$-equivalent emissions as a surrogate indicator of climate impacts, while modeling approaches (blue-to-gray area) look more directly into the temperature change and other physical and social impacts as an indicator of climate impacts. Gray boxes show factors, such as emissions and temperature change, along the cause-effect chain of climate change from left to right (green-to-gray bar), following Fig. 8.27 of the IPCC AR5. Solid arrows represent cause-effect relationships between such factors. The arrow where emission metrics are applied is highlighted in red. If GWP is used, the conversion from non- $\mathrm{CO}_{2}$ emissions to $\mathrm{CO}_{2}$-equivalent emissions implicitly uses radiative forcing calculations using models (dashed arrow). Likewise, if GTP and $\mathrm{GCP}$ are used, the $\mathrm{CO}_{2}$-equivalent conversion relies on temperature and mitigation cost calculations using models, respectively (dashed arrows). For the purpose of clarity, only first-order relationships are shown. Temporal and spatial aspects are suppressed in the figure. 
aggregated integrated assessment model $(\operatorname{IAM})(22,23)$ that accounts for distinct atmospheric characteristics and emission abatement costs of $\mathrm{CO}_{2}$ and $\mathrm{CH}_{4}$ among other features. This model is used to derive a cost-effective pathway for a given temperature target and explore how the use of metrics can influence the pathway and mitigation costs. The analysis was performed for a contrasted range of pathways toward the Paris Agreement temperature target levels, including those substantially overshooting the $2{ }^{\circ} \mathrm{C}$ target level temporarily, which were not assessed in the IPCC Special Report "Global warming of $1.5^{\circ} \mathrm{C}$ ” (SR15) (24). Low overshoots (i.e., exceedance warming of up to $0.1^{\circ}$ or $0.2^{\circ} \mathrm{C}$ ) have been considered in previous related studies (25-28); however, higher overshoots above $2^{\circ} \mathrm{C}$, reflecting the current policy trend [i.e., $\sim 3^{\circ} \mathrm{C}$ warming by $2100 ;(29,30)$ ], have not been considered before despite their increasing likelihood. Overshoot pathways are intended to illustrate the relatively unexplored scenarios in which the world would fail to take stronger near-term climate actions that would have been consistent with the Paris Agreement; however, it would later engage in very deep mitigation, allowing a recovery from overshoot.

Examining the costs of using metrics in light of overshoot possibilities illuminates their path dependency. According to our IAM, the cost-effective metric for $\mathrm{CH}_{4}$ (i.e., the ratio of the shadow prices of $\mathrm{CO}_{2}$ and $\mathrm{CH}_{4}$ ), which is known to be time-dependent under stabilization pathways (7), shows larger temporal variations under overshoot pathways. The path and time dependency of cost-effective metrics led us to explore further how the choice of conventional $\mathrm{CH}_{4}$ metrics such as GWP100, GWP50, and GWP20 can be adapted in policy setting to evolving future pathways. We show that the adaptive use of metrics, changing from GWP100 to other shorter time horizon GWPs in the future, can save mitigation costs, compared to the permanent use of GWP100. Nevertheless, GWP100 appears to be a reasonably good approximation of cost-effective metrics for the next few decades. Hence, our study suggests that the UNFCCC and parties to the Paris Agreement should consider periodically assessing the appropriateness of the choice of GHG metrics as future options unfold to pursue a cost-effective implementation of emissions abatement options. Such assessments could be considered as part of the recurring global stocktake processes within the UNFCCC over the coming decades, where future mitigation actions and ambition levels are discussed among parties because they are related to potential revisions of the adopted GHG metrics.

\section{Aligning emission metrics with emerging mitigation strategies}

The framing of climate policy-relevant research has changed drastically with the adoption of the Paris Agreement in 2015 (31), which calls for holding the global warming well below $2^{\circ} \mathrm{C}$, pursuing efforts to limit the warming to $1.5^{\circ} \mathrm{C}$ relative to preindustrial levels (Article 2.1), and achieving global net zero anthropogenic GHG emissions during the latter half of this century (Article 4.1). The temperature targets have led to massive research efforts on low-temperature stabilization pathways, as assessed in the IPCC SR15. The SR15 highlighted the need for global net zero anthropogenic $\mathrm{CO}_{2}$ emissions by 2050 to achieve the $1.5^{\circ} \mathrm{C}$ goal. An increasing number of countries, municipalities, sectors, and individual firms adopted so-called "carbon neutrality" or zero emissions, for mid-century.

In contrast to these ambitious goals, the current policies imply that the global warming may reach $3^{\circ} \mathrm{C}$ by the end of this century $(29,30)$. While there are pressures to ratchet up the NDCs $(32)$, even planned mitigation efforts may face challenges upon implementation. The demonstrations by the Yellow Vests ("gilets jaunes" in French), triggered in November 2018 by the opposition to rising fuel tax in France, were illustrative of the difficulties of implementing climate policies. In 2020, the global $\mathrm{CO}_{2}$ emissions dropped relative to the 2019 level as a result of the pandemic of coronavirus disease 2019 (33). To enable emission reductions for a longer term, a set of green policies have been proposed as part of the recovery packages (34), but it is yet unclear how the long-term emission trend will unfold. Given these circumstances, as argued by others before (35-37), it is imperative to consider a broad range of pathways, not only stabilization (i.e., nonovershoot) and low overshoot pathways toward the $2^{\circ}$ and $1.5^{\circ} \mathrm{C}$ targets but also higher overshoot pathways, under which the temperature exceeds the target levels substantially before eventually settling there. Pathways overshooting the $1.5^{\circ} \mathrm{C}$ target and staying below $2^{\circ} \mathrm{C}$ can be interpreted as being in line with the Paris Agreement's long-term goal, while pathways substantially overshooting the $2^{\circ} \mathrm{C}$ target should be seen as being in violation of the goal. Nevertheless, such overshoot pathways must be considered plausible if ambition levels are not rapidly increased in the next decades. However, higher overshoot pathways, particularly those substantially exceeding the $2^{\circ} \mathrm{C}$ level, are underrepresented in the recent literature or rarely found in IAM studies conducted after the adoption of the Paris Agreement. GHG metrics were evaluated for various temperature and forcing targets $(18,25,27,38)$, with a few studies analyzing metrics directly applied to the net zero GHG target $(23,39)$. However, to our knowledge, metrics have not been investigated under a range of plausible overshoot pathways in relation to the Paris Agreement goals.

At the 24th session of the Conference of the Parties (COP24) of the UNFCCC, GWP100 was adopted as the common metric to be used for the implementation of the transparency framework of the Paris Agreement [paragraph 37 of the Annex to Decision 18/CMA.1 (20)]. The transparency framework includes guidelines for parties' GHG inventories, scenario analyses, and reporting on implemented policies and measures, with the purpose of tracking progress with the implementation of each party's NDC and informing the global stocktake [paragraph 1 of the Annex to Decision 18/CMA.1; (20)]. To be more specific, the guideline states that the GWP100 values shall be used as provided by the IPCC Fifth Assessment Report (AR5) (or a subsequent IPCC report upon future agreement), an update from those provided by the IPCC Second or Fourth Assessment Report (SAR or AR4) currently in use at the UNFCCC (40). The COP24 decision gave an option for using other metrics in addition to GWP100, noting the global temperature change potential (GTP) (8) as an example, which equates the emissions of different climate forcers with respect to the final temperature change at the end of a chosen time horizon after a pulse emission.

While the decision has been made on the common metrics for the implementation of the Paris Agreement, it is important to emphasize that the COP24 decision contains a provision for reviewing and updating the guidelines for the transparency framework by 2028 at the latest [paragraph 3 of decision 18/CMA.1; (20)] that could allow a shift from GWP100 toward another type of common metrics, provided that parties wish to pursue such an update that goes beyond the current decision. It should be further noted that the topic of common metrics is still listed as one of the sub-items of methodological issues in the draft provisional agenda for the 52nd session of the Subsidiary Body of Scientific and Technological Advice 
(SBSTA52) (41), an advisory body to the UNFCCC on scientific and technical matters. The negotiations at SBSTA did not reach conclusions at the previous session, and the agenda item is automatically pushed to the next session planned for 2021. Nevertheless, the draft text (42) proposed by the Chair of the previous session suggests that parties recognize the importance of synchronizing metrics used for different purposes within the UNFCCC, guided by the decision made for the transparency framework of the Paris Agreement. At the same time, the draft text shows openness to considering future scientific findings on metrics in IPCC AR6, as well as views of parties and observers on the implications of the choice of metrics for climate change policy. In response, a group of scientists made a voluntary submission to UNFCCC to encourage SBSTA52 to initiate and conclude a review of common metrics, via a dialogue between policymakers and the research community (43).

\section{RESULTS \\ Cost-effective metrics under stabilization and overshoot pathways}

We present a first analysis of the implications of using different emission metrics under stabilization and overshoot pathways. To start with, we show the global cost-effective potential $(\mathrm{GCP})(7,44)$, the economic metric that can be derived from a cost-effective pathway of interest, which serves as a benchmark in the analysis that follows. Unlike GWP and GTP, which require only a physical model to be estimated, GCP requires calculations of both climate change and mitigation costs with an IAM. Our study uses the Aggregated Carbon Cycle, Atmospheric Chemistry, and Climate model (ACC2) version $4.3(22,23)$ (Methods), a simple IAM that describes major physical and biogeochemical processes in the global earth system, as well as the economic relationships between mitigation levels of GHG emissions and associated costs. More specifically, ACC2 consists of a global climate and carbon cycle model of reduced complexity combined with an economic module containing marginal abatement cost (MAC) curves for $\mathrm{CO}_{2}, \mathrm{CH}_{4}$, and $\mathrm{N}_{2} \mathrm{O}(38,45)$ (fig. S2). This model allows us to generate cost-effective emission pathways for given temperature targets under a single modeling framework, unlike other more complex IAMs that are not dynamically coupled with a climate and carbon cycle model. The model describes primarily global aspects, providing no details in regional and sectoral changes. The temporal resolution of the model is 1 year. Limitations associated with the MAC curve approach are discussed in Methods and elsewhere $(46,47)$. It needs to be kept in mind that our pathways are illustrative only and should be interpreted as such.

We generated $2^{\circ} \mathrm{C}$ stabilization, as well as $2^{\circ}$ and $1.5^{\circ} \mathrm{C}$ overshoot pathways, on the basis of a cost-effectiveness principle by minimizing the net present value costs of abating the GHG emissions over time as calculated from the MAC curves (Fig. 2A, table S1, and fig. $\mathrm{S} 3$ ). Figure $2 \mathrm{~A}$ shows five such illustrative pathways in comparison to those considered in SR15 (48) (Methods). We interpret the two temperature targets stated in Article 2 as stabilization targets (i.e., stable temperatures) in our analysis. We assume two different overshoot levels requiring the warming not to exceed the respective target after 2100 or 2150 . For example, we applied a $2^{\circ} \mathrm{C}$ target beginning in 2100 in the cost-effective pathway calculation to derive our $2^{\circ} \mathrm{C}$ pathway with overshoot until 2100 . Thus, the length and magnitude of temperature overshoot were not externally set in our analysis but rather an outcome of our internal cost-effective pathway calculations,
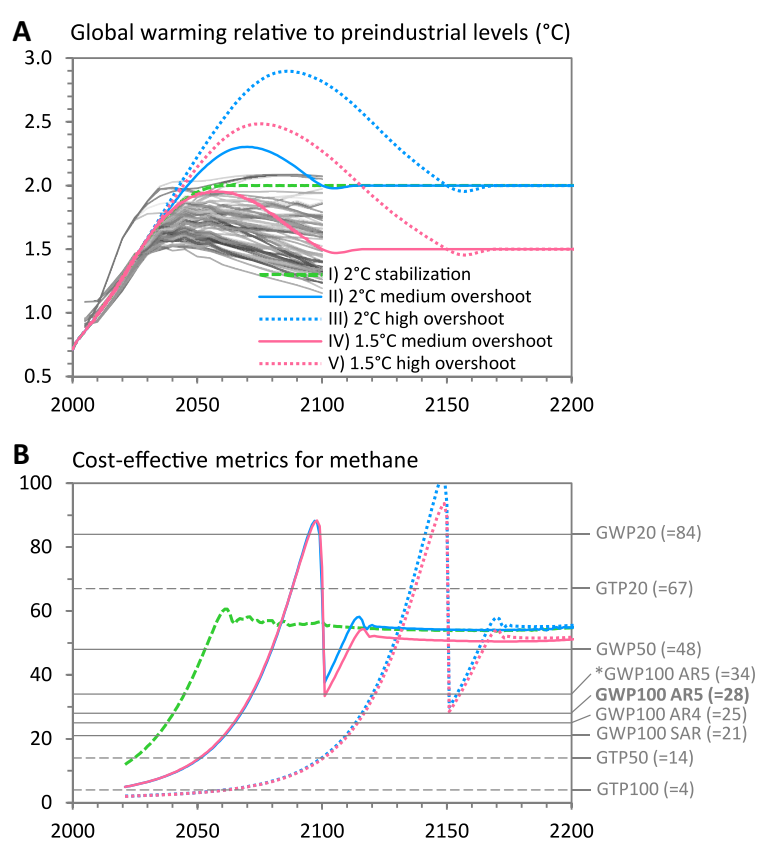

Fig. 2. Temperature stabilization and overshoot pathways and cost-effective metrics for $\mathbf{C H}_{4} \cdot \operatorname{In}(\mathbf{A})$, dashed green lines show the case in which the $2^{\circ} \mathrm{C}$ target is achieved without overshoot. Blue and pink lines indicate the cases in which the temperature stabilizes at the $2^{\circ}$ and $1.5^{\circ} \mathrm{C}$ warming levels after overshoot, respectively. Solid and dotted lines correspond to the cases where overshoot is assumed unavoidable before 2100 and 2150, respectively (termed "medium" and "high" overshoot, respectively, in reference to "low" overshoot considered in the IPCC SR15). Gray lines in the background indicate the range of temperature pathways considered in SR15 (Methods). In (B), the $\mathrm{CH}_{4} \mathrm{GCPs}$ under the five pathways [line designations as in (A)] are shown. GWPs and GTPs with the time horizons of 20,50, and 100 years are shown in solid and dashed gray lines, respectively, as a reference for comparison. The metric values indicated in parentheses are taken from Tables 8.A.1 and 8.SM.17 of the IPCC AR5 (i.e., those without inclusion of climate-carbon feedbacks for non- $\left.\mathrm{CO}_{2}\right)$, unless noted otherwise. For GWP100, the panel shows four different values including those from earlier IPCC Assessment Reports (ARs). The GWP100 value in AR5 with inclusion of climate-carbon feedbacks for non- $\mathrm{CO}_{2}$ is indicated by * and taken from Table 8.7 of AR5.

reflecting various model assumptions (fig. S6) including, most notably, the limits to negative $\mathrm{CO}_{2}$ emissions. The time scale beyond 2100 is essential for investigating a broad range of overshoot pathways aligning the current trend toward a $3^{\circ} \mathrm{C}$ warming before the end of this century.

Of the five illustrative pathways, only two pathways, namely, the $2{ }^{\circ} \mathrm{C}$ stabilization pathway and the $1.5^{\circ} \mathrm{C}$ medium overshoot pathway, are generally considered as being consistent with the Paris Agreement. The remaining three pathways are intended to cover the relatively unexplored but increasingly relevant range reflecting current policy levels. These three cases illustrate how the pathway would appear if climate actions were limited in the near term but were enhanced strongly later to still aim for the target levels. The three pathways show a recovery from overshoot as derived under our model assumptions; however, the recovery, in reality, is contingent on the feasibility of very deep mitigation (49-51). The GHG emissions (based on GWP100) in these three pathways go below zero by around the turn of this century (fig. S3J), which may be interpreted as being consistent with the Paris Agreement emission target for the latter half of this century (23); however, these cases should be regarded 
as a violation of the Paris Agreement because of the overshoot above $2^{\circ} \mathrm{C}$. Note that no $1.5^{\circ} \mathrm{C}$ stabilization pathway is included in our analysis because the $1.5^{\circ} \mathrm{C}$ target cannot be achieved without overshoot in our model unless we relax the abatement constraints (Methods) (23). The earliest possible year to achieve the $1.5^{\circ} \mathrm{C}$ target is 2085 after an overshoot of $0.35^{\circ} \mathrm{C}$ (in 2049) under our default model assumptions. Sensitivities of these pathways to underlying assumptions are discussed where appropriate below.

Under each of these five pathways, we calculated GCP, the metric most consistent with the cost-effectiveness principle. GCP is defined as the ratio of the willingness to pay for emitting an additional unit of a gas of interest to that of $\mathrm{CO}_{2}$ at each point in time under a cost-effective pathway, reflecting the ratio of the emission shadow prices between the two gases. We implicitly assume a globally connected emission market (or a global emission tax system) for $\mathrm{CO}_{2}$, $\mathrm{CH}_{4}$, and $\mathrm{N}_{2} \mathrm{O}$. In this analysis, we focus on the outcome of $\mathrm{CH}_{4}$, a potent GHG whose atmospheric response time is substantially shorter than that of $\mathrm{CO}_{2}$ (52). The outcome of $\mathrm{N}_{2} \mathrm{O}$, a long-lived GHG, is different but does not strongly influence the overall outcome, so it will not be analyzed here.

Our calculations show that, under the $2^{\circ} \mathrm{C}$ stabilization pathway, the $\mathrm{CH}_{4} \mathrm{GCP}$ rises over time until the temperature reaches $2^{\circ} \mathrm{C}$ (Fig. 2B) $(7,12,38)$. GCP for $\mathrm{CH}_{4}$ is larger than GTP100 throughout the period and becomes larger than GWP100 (i.e., 28 in the IPCC AR5) after 2040. After the stabilization in 2063, GCP stays at an approximately constant level near GWP50. For the overshoot pathways, the rise in the $\mathrm{CH}_{4} \mathrm{GCPs}$ occurs later and more drastically than under the stabilization pathway. GCPs grow after the temperature peak, until immediately before the temperature returns to the target levels, with a peak exceeding GWP20. The rise in the $\mathrm{CH}_{4}$ GCPs is associated with the priority given to $\mathrm{CH}_{4}$ mitigation to lower the temperature to the target level (fig. S4). This is because of the rapid effect that $\mathrm{CH}_{4}$ mitigation has on the temperature, but other factors also come into play. This deep $\mathrm{CH}_{4}$ abatement before the stabilization was not observed under the stabilization pathway. Once the target is met, the temperature does not have to be reduced further in our cost-effectiveness approach, which reduces the relative incentive to abate $\mathrm{CH}_{4}$ emission, resulting in the abrupt drop in GCPs. The temperature is slightly decreased further after the stabilization due to the inertia of the physical earth system before it finally settles at the target level.

Our results from the five illustrative pathways of Fig. 2 show that the $\mathrm{CH}_{4} \mathrm{GCP}$ is time-dependent, rises till stabilization occursparticularly strongly so under the overshoot pathways-and then becomes stable after stabilization. The long-term evolution of GCP depends on the type of pathways. Overshoot pathways imply larger changes in GCP. These results also suggest that the evolution of GCP is largely determined by the year when the stabilization is eventually achieved [related insight in (12)] and relatively insensitive to the target level (fig. S5), but not at all influenced by the year of the temperature peak. We further explore the sensitivity of GCP with respect to the assumptions on the equilibrium climate sensitivity $\left(2^{\circ}\right.$ and $4.5^{\circ} \mathrm{C}$, with $3^{\circ} \mathrm{C}$ by default), the discount rate $(2$ and $6 \%$, with $4 \%$ by default), and the MAC curves (one case assuming a 50\% higher $\mathrm{CO}_{2}$ MAC curve and $50 \%$ lower $\mathrm{CH}_{4}$ and $\mathrm{N}_{2} \mathrm{O}$ MAC curves than the respective standard MAC curves and the opposite case assuming a 50\% lower $\mathrm{CO}_{2} \mathrm{MAC}$ curve and $50 \%$ higher $\mathrm{CH}_{4}$ and $\mathrm{N}_{2} \mathrm{O}$ MAC curves than the respective standard MAC curves) (Methods). GCP is sensitive to the assumptions on the discount rate and the equilibrium climate sensitivity while being less sensitive to the MAC curves (12); however, the general behavior of GCP described above holds under different assumptions in our IAM (fig. S6).

\section{The cost-effectiveness of GWPs and GTPs}

The time-dependent GCP is the cost-effective metric by construction, as it is derived directly from the cost-effective pathway calculation. We now estimate the economic implications of continuing with the time-invariant GWP100 currently in use and agreed to be used in the Paris Agreement implementation. The economic costs of using GWP100 can be calculated by imposing the metric in the pathway calculation, namely, on the ratios of the MACs of associated gases at each point in time. That is, one keeps the $\mathrm{CH}_{4} \mathrm{MAC}$ in each year to be larger than the $\mathrm{CO}_{2} \mathrm{MAC}$ in the same year by a factor of the $\mathrm{CH}_{4}$ GWP100. Likewise, one applies the $\mathrm{N}_{2} \mathrm{O}$ GWP100 to fix the ratio of the $\mathrm{N}_{2} \mathrm{O}$ and $\mathrm{CO}_{2}$ MACs over time (but this constraint on $\mathrm{N}_{2} \mathrm{O}$ has only a small impact on the overall results). Thus, the use of metrics poses additional constraints in the pathway calculation, giving rise to higher mitigation costs than those without the use of metrics. The cost increment (in terms of the discounted net present value) as a result of the metric use, relative to the lowest costs without the use of metrics (or equivalently, with the use of GCP), is analyzed as the "cost of metrics" in our study. Note that the use of metrics influences the emission and temperature pathways and can even affect the feasibility of the temperature target. Thus, we made further assumptions to analyze the cost of metrics as explained in Methods. The methodology described above follows several previous studies (27, 53-55), but there are variations in the methodologies for metric cost calculations, requiring attention when the outcomes are compared. For example, some previous studies $(25,26)$, using more complex IAMs than the one used here, used $\mathrm{CO}_{2}$-equivalent emission targets derived from different metrics, instead of directly constraining the ratios of relevant gas prices, to estimate the costs of using metrics.

Previous studies showed that the use of GWP100 does lead to some but not a strong disadvantage in terms of global total abatement costs under stabilization pathways (including small overshoot pathways) $(25-28,53-55)$. While we confirm this finding \{Fig. 3; $1.4 \%$ $[0.6 \%, 2.5 \%]$ higher global total mitigation costs (till 2200) than the least cost case, with sensitivity ranges in square brackets with respect to different assumptions on the climate sensitivity, the discount rate, and the MAC curves (Methods)\}, we find that the additional costs of using GWP100 become larger under overshoot than under stabilization pathways (e.g., $4.0 \%$ [2.5\%, 5.5\%] under the $1.5^{\circ} \mathrm{C}$ high overshoot pathway). The costs of using GWP20 are also higher under overshoot than under stabilization pathways (e.g., 10.9\% [9.0\%, $11.7 \%$ ] under the $1.5^{\circ} \mathrm{C}$ high overshoot pathway). It is worth noting that the use of GWP20, which is sometimes promoted because of concern over the near-term warming (56), yields larger long-term total costs than that of GWP100 under all pathways, including sensitivity cases (fig. S7, except for the $2^{\circ} \mathrm{C}$ stabilization pathway with a discount rate of 6\%), reflecting high $\mathrm{CH}_{4}$ abatement driven by this metric. The use of other time-invariant metrics, in particular, GTP100, creates additional costs of over $10 \%$ in all cases (fig. S8, except for those using the discount rate of $2 \%$ ). For longer time horizons, the use of GWP500 and GTP500 leads to additional costs of over 8 and $20 \%$, respectively, under all pathways (table S2 and figs. S9 and S10). The high costs associated with the use of long time horizon metrics including GTP100 are due to the need for more $\mathrm{CO}_{2}$ abatement at a higher cost to compensate for $\mathrm{CH}_{4}$ emissions valued low $(27,28)$. 

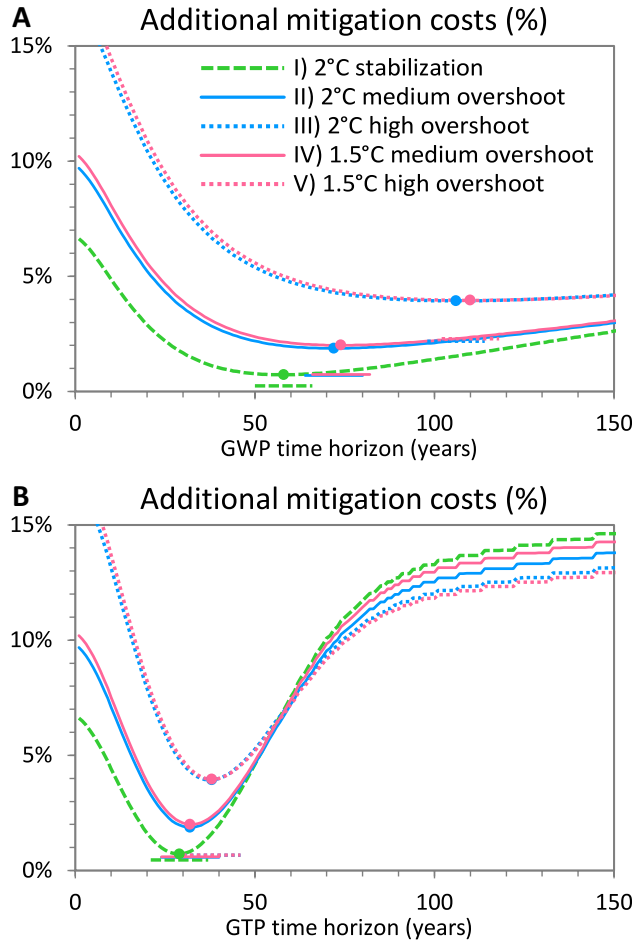

Fig. 3. Additional mitigation costs of using GWP and GTP with a range of time horizons under the stabilization and overshoot pathways. The additional mitigation costs (in percent) with the use of GWP and GTP relative to the lowest costs without the use of metrics (or equivalently, with the use of GCP) are shown in (A) and (B), respectively. The results with the time horizons between 1 and 150 years are presented. The minimum under each pathway, which is marked by a filled circle, indicates the optimal time horizon and the residual additional mitigation costs. The short horizontal bars vertically aligned with each minimum point indicate the additional mitigation costs of using best available GWPs (from the default set of three metrics GWP100, GWP50, and GWP20) (A) or best available GTPs (from the default set of GTP100, GTP50, and GTP20) (B) under each pathway. All horizontal bars follow the legend in (A).

We further show the "optimal" time horizon for GWP or GTP, which reduces the total mitigation costs as much as possible if implemented throughout the period. We note that a related but different definition of the optimal time horizon is used in (10). We repeated the metric cost calculations by changing the metric time horizon for $\mathrm{CH}_{4}$ and $\mathrm{N}_{2} \mathrm{O}$ between 1 and 500 years with a 1-year interval (a 5-year interval above 150 years). We then identified the optimal time horizon leading to lowest costs under each pathway. The GWP and GTP values for $\mathrm{CH}_{4}$ and $\mathrm{N}_{2} \mathrm{O}$ with a time horizon from 1 to 500 year(s) were calculated on the basis of Section 8.SM.11 of the IPCC AR5 (for metrics without inclusion of climate-carbon feedbacks for non$\mathrm{CO} 2$ ). The calculated metric values (fig. S11) reproduced those reported in Tables 8.A.1 and 8.SM.17 of the IPCC AR5. The values of GWPs and GTPs with long time horizons need to be taken cautiously because the uncertainty in metric values increases with the time horizon $(52,57)$.

The optimal time horizon depends on the pathways, ranging between $58[45,86]$ and $110[92,118]$ years for GWP and between 29 $[25,34]$ and $38[36,40]$ years for GTP (Fig. 3). In both metric cases, the longer the period before the stabilization year occurs, the longer the optimal time horizon is. The range is more confined for GTP than for GWP, largely reflecting the different correspondence between time horizons and metric values (fig. S11). There is, however, still about $4 \%$ additional costs even with the use of the optimal time horizon under the high overshoot pathways (for both GWP and GTP). This finding suggests that, no matter which time horizon is chosen, the use of a single GWP or GTP departs by several percent from cost-effectiveness under overshoot pathways. This arises from the fact that the temporal variations in GCPs under overshoot pathways cannot be well approximated by a single static GWP or GTP. It may be worthwhile to consider the dynamic GTP whose time horizon is kept until the time of stabilization $(25,27)$ because it captures the rising trend toward the point of stabilization, which can contribute to cost saving. It is known that a dynamic GTP can exceed GCP values under stabilization pathways $(12,38)$ and may follow the sharp rise in GCP under overshoot pathways. However, we did not analyze it here because it is unclear how to apply a dynamic GTP in the poststabilization period.

The additional costs discussed above may appear rather modest, and the choice of pathways has a much larger impact on the absolute costs than the choice of metrics (figs. S9C and S10C). Nevertheless, the choice of metrics strongly influences the cost distributions over time and across gases (with the exception that the impacts on the $\mathrm{N}_{2} \mathrm{O}$ abatement costs, emissions, and concentrations are generally small; figs. $S 12$ to $S 16)$. Previous studies $(25,26,28)$ reported remarkable regional and sectoral impacts from the choice of metrics, despite relatively small global impacts. Our results imply that these regional and sectoral variations in cost could be larger under overshoot pathways.

\section{Best available metrics among the IPCC set}

From a practical perspective, it is useful to interpret our theoretical cost-effective outcome through the eyes of well-established metrics from the IPCC AR5. We thus translated the GCP results (Fig. 2B) in terms of GWPs (or GTPs) with representative time horizons of 20, 50 , and 100 years. In other words, we selected "best available GWPs (or GTPs)" from AR5, whose values are most proximate to our GCPs in absolute terms at each point in time, under the assumption that these metric values from the IPCC will not change in the future. In the experiment, we treated GWPs and GTPs separately because these are structurally different. We mainly analyze the results from GWPs, which are predominantly used in policies. Our approach was inspired by a combined use of metrics from the IPCC for climate impact assessments (58-63).

Under the $2^{\circ} \mathrm{C}$ stabilization pathway, best available metrics change from GWP100 to GWP50 (or from GTP50 to GTP20) shortly before 2050 (Fig. 4). Under the overshoot pathways, changes in best available metrics are more drastic than under the stabilization pathway, reflecting the larger changes in GCPs with overshoot. Differences in the transitions of best available metrics come from different stabilization years. Another interesting outcome is that GWP100 is chosen from the onset under all pathways, a robust finding except regarding the assumed set of available metrics (Methods; figs. S17 to S20). If we instead assume six metrics to choose from (i.e., GWP500, GWP200, GWP100, GWP50, GWP20, and GWP10), it chooses GWP500 or GWP200 at the beginning. On the other hand, if we assume just two metrics in the basket of choice (i.e., GWP100 and GWP20), it chooses GWP100 for most of the period under all pathways, except for some periods shortly before the temperature stabilization (fig. S17). 
A Best available GWPs

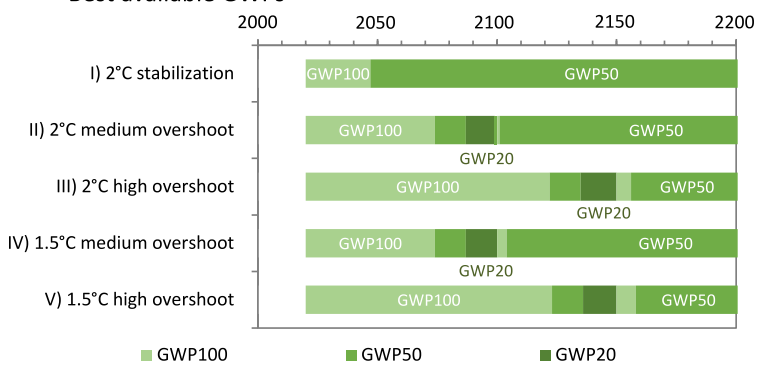

B Best available GTPs

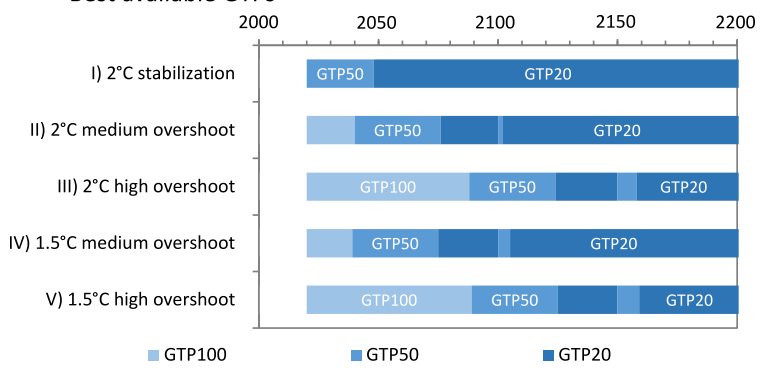

Fig. 4. Choices of representative GWPs and GTPs most proximate to costeffective metrics under the stabilization and overshoot pathways. GWPs and GTPs with three representative time horizons (i.e., 20, 50, and 100 years) from the IPCC AR5 are considered. One of the three GWPs and GTPs [in (A) and (B), respectively], whose value is closest to the corresponding GCP in absolute terms, is shown under each pathway. The color is designated according to the time horizon as indicated in the legend at the bottom of each panel. On the basis of (80), we refer to the IPCC metric values without inclusion of climate-carbon feedbacks for non$\mathrm{CO}_{2}$ gases (Tables 8.A.1 and 8.SM.17 of the IPCC AR5) while noting that it is unclear whether the COP24 decision [paragraph 37 of the Annex to Decision 18/CMA.1; (20)] refers to metric values with or without inclusion of climate-carbon feedbacks for non- $\mathrm{CO}_{2}$ gases. It should also be noted that the IPCC AR5 does not endorse any metrics assessed.

Is it cost-effective to move from a fixed approach permanently using GWP100 to a flexible approach allowing future revisions of the metric time horizon? While the additional costs of continuously changing time horizons, such as the dynamic GTP, have been investigated previously $(25,27)$, those of discretely changing time horizons, which is arguably more policy relevant, have not been considered before. We show here that it is cost-effective to shift from the fixed to the flexible approach under all pathways, also taking account of their sensitivity cases (Fig. 5; all outcomes, that is, five representative outcomes shown in large circles, as well as sensitivity outcomes expressed as error bars in horizontal and vertical directions, are consistently on the right of the 1:1 line). The cost improvement is larger under overshoot than under stabilization pathways. The assumed set of available metrics influences such benefit. Under the $1.5^{\circ} \mathrm{C}$ high overshoot pathway (as the most extreme case), choosing from a set of six GWPs instead of the default set of three GWPs reduces the additional costs from $2.3 \%$ down to $0.46 \%$. On the other hand, choosing from a set of two GWPs increases the additional costs to $2.5 \%$ (but still below $4.0 \%$, the costs of using only GWP100 under this pathway). The assumption on the discount rate has a larger impact on the results than those on the climate sensitivity and the MAC curves; however, the economic benefit for the flexible approach, relative to the permanent use of GWP100, is retained in all cases.
We further find that the flexible approach using best available metrics will cost less than any fixed approach, including one using the metric with the optimal time horizon. In the former case, the choice is limited to three GWPs, but it can be changed at any time. In the latter case, the choice can be any GWP with a time horizon of 1 to 500 years, but it cannot be changed with time. Under all pathways including sensitivity cases (a total of 28 cases), the flexible use of best available GWPs is less costly than the fixed use of a single GWP with the optimal time horizon (Fig. 3 and fig. S7). The same finding was obtained from a corresponding experiment using GTPs, except for one case assuming the discount rate of $2 \%$ (Fig. 3 and fig. S8). Our results point to a fundamental limit associated with the fixed use of metrics and further support the flexible use of metrics under a range of mitigation pathways.

\section{DISCUSSION \\ Implications for the Paris Agreement implementation}

Our new findings support the provision of flexibility in the implementation of the Paris Agreement, especially toward metrics with shorter time horizons that can reflect future changes in long-term pathways. We argue that this aspect of mitigation planning could be considered at the recurring global stocktake processes (first in 2023 and then every 5 years) by including an assessment of the costeffectiveness of the GHG metric choice. Following the COP24 decision [decision 19/CMA.1; (20)], the global stocktake serves as a tool for increasing the ambition needed from parties to achieve the goals of the Paris Agreement. The process is supported by a technical assessment to include opportunities for enhanced mitigation action (two sessions in November 2022 and July 2023 for the first global stocktake occurrence; the deadline for materials to be considered in the technical assessment is expected to be August 2022). Promoting cost-effective emission abatement is important in this process because it can identify such opportunities and may enable increased ambition levels from parties. Hence, we suggest that an assessment of the cost-effectiveness of GHG metrics for future mitigation strategies could be included as an input to the technical assessment supporting the global stocktake. When deemed necessary, the global stocktake could recommend a revision of the Paris Agreement's transparency framework to shift toward GWPs with shorter time horizons. We do not know yet the long-term pathway at the time of the upcoming first global stocktake; however, an inclusion of such an agenda item already at the onset of this recurring process could allow the necessary assessments in time to inform subsequent sessions as the long-term pathway unfolds.

A change in metric values is not unprecedented at the UNFCCC. A small revision is already implicit in the COP24 decision to update GWP100 values to those in AR5 (and those in any future IPCC reports), which means that the $\mathrm{CH}_{4}$ GWP100 will be revised from 21 (SAR) or from 25 (AR4) to 28 (AR5) [or to 34 (AR5), depending on the treatment of climate-carbon feedbacks; (64)]. However, the long-term metric revisions indicated by our analysis are of a different nature and much larger than the proposed update of GWP100 values. This further highlights the need for GWP estimates for different time horizons to be continuously provided by the IPCC, irrespective of scientific advances in other types of metrics.

It is important to note that our suggestion is not in conflict with the use of GWP100 in the coming decades, except if we additionally consider GWP500 and GWP200. Rather, we argue for a long-term 


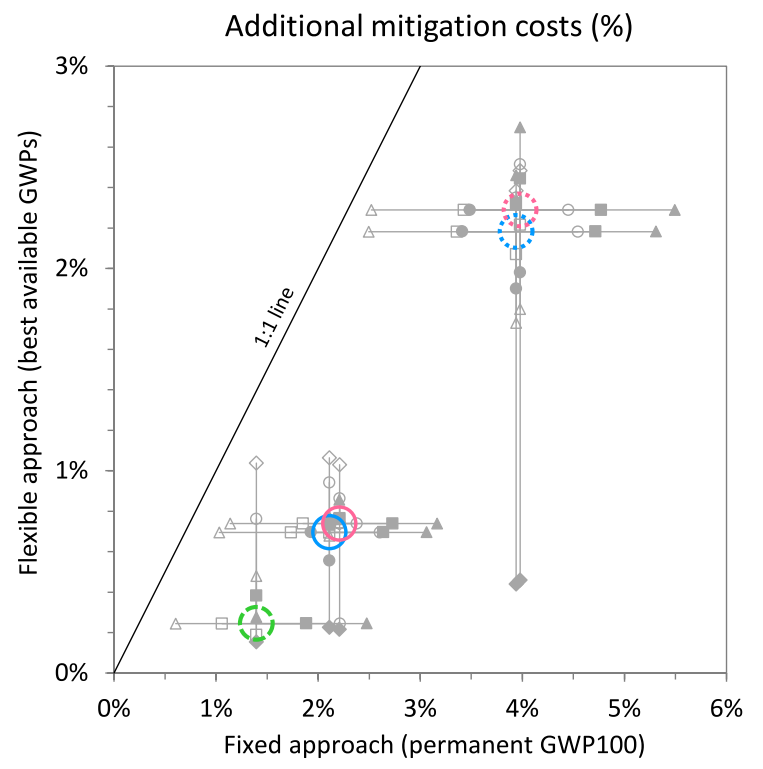

Representative outcomes

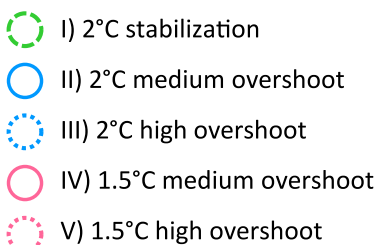

\section{Sensitivity ranges}

$\diamond \rightarrow$ Available metrics (2 metrics; 6 metrics)

$-\longrightarrow$ Equilibrium climate sensitivity $\left(2^{\circ} \mathrm{C} ; 4.5^{\circ} \mathrm{C}\right)$

4 Discount rate (2\%; 6\%)

- MAC curves (50\% higher $\mathrm{CO}_{2}$ and $50 \%$ lower $\mathrm{CH}_{4}$ and $\mathrm{N}_{2} \mathrm{O}$ MAC curves; $50 \%$ lower $\mathrm{CO}_{2}$ and $50 \%$ higher $\mathrm{CH}_{4}$ and $\mathrm{N}_{2} \mathrm{O}$ MAC curves)

Fig. 5. Additional mitigation costs of shifting from the permanent use of GWP100 to the more flexible use of GWPs. This scatterplot shows the additional mitigation costs (in percent) with the permanent use of GWP100 ( $x$ axis) versus those with the use of best available GWPs ( $y$ axis), both relative to the lowest costs without the use of metrics (or, equivalently, with the use of GCP). The 1:1 line is indicated in black. The outcomes under default assumptions are indicated in large color circles as representative outcomes. The sensitivity ranges are shown in both horizontal and vertical directions and characterized by categories. In the default set of assumptions, the number of available metrics (or time horizons) is three (i.e., GWP100, GWP50, and GWP20), the equilibrium climate sensitivity is $3^{\circ} \mathrm{C}$, and the discount rate is $4 \%$. The assumptions in the sensitivity cases are indicated in parentheses in the legend. Note that horizontal error bars indicate their respective sensitivity ranges only for the fixed approach. The same goes for vertical error bars indicating sensitivity ranges only for the flexible approach. By definition, sensitivity ranges, with respect to the number of available metrics, appear only to the vertical direction. Note also that the $2^{\circ} \mathrm{C}$ stabilization pathway and the $1.5^{\circ} \mathrm{C}$ medium overshoot pathway are not considered in the case of $4.5^{\circ} \mathrm{C}$ climate sensitivity because these pathways are infeasible with the high climate sensitivity.

benefit for allowing flexibility in the future choice of metrics, fundamentally because the future pathway is unknown owing to the inherent uncertainties in the climate system and the unpredictability of future social, economic, and technological developments, and technically because a stabilization year, which is crucial for determining the metric, is not explicitly given in the Paris Agreement text. Even if a $2^{\circ}$ and $1.5^{\circ} \mathrm{C}$ pathway is followed within this century and assuming that global cost-effectiveness is an important criterion for guiding international climate policy, the metric would still be time-dependent in response to changing mitigation priorities, particularly under overshoot pathways.

We further note the newly proposed metrics such as GWP* (15) or its variation (65), which can enhance the accuracy of how $\mathrm{CO}_{2}$ and SLCF emissions are aggregated in terms of the implied warming $(18,66)$. The GWP* approach in essence compares $\mathrm{CO}_{2}$ emissions of a certain year with a change in the rate of SLCF emissions over a preceding period (e.g., for 20 years). While such new metrics are intensively debated in recent literature, it is yet unclear to what extent they would require revisions of the Paris Agreement itself to accommodate the need for considering SLCF emissions occurring in preceding decades, if they are applied to the mitigation context that our analysis deals with. Shifting among conventional GWPs with different time horizons seems to be a more practical way of ensuring a cost-effective implementation of the Paris Agreement.

Our approach assumes a global actor, without considering the potentially heterogeneous behaviors of individual actors toward time-dependent metrics in the absence of perfect knowledge (67). Nevertheless, cost-effective metrics presented here serve as a useful benchmark, against which more transparent metrics such as GWPs can be evaluated. Our cost-effective metrics and the corresponding shifts of GWPs depend on assumptions in the IAM required to calculate future pathways. However, as presented through various sensitivity analyses, the cost advantage for adapting the metric to evolving future was shown to be robust under a broad range of pathways. Our analysis dealt with overshoot pathways more prominently than previous related studies, putting a spotlight on scenarios where the Paris Agreement targets were not achieved owing to limited nearterm climate actions; however, the main conclusion on the advantage of the flexible metric approach is not biased by the choice of pathways and was shown to be valid under all pathways. Our findings suggest that, while the possibility of metric revisions should not impede the political progress toward the Paris Agreement implementation or disturb market-based mechanisms relying on metrics, there should be room for consideration of metric revisions in the future potentially as part of the global stocktake processes within the UNFCCC. The flexible use of metrics can better serve for a broad range of pathways under uncertain circumstances, including non-ideal overshoot cases.

\section{METHODS \\ Model ACC2}

ACC2 represents four domains of the global earth system: (i) physical climate system, (ii) carbon cycle system, (iii) atmospheric chemistry system, and (iv) economy system. The first three domains are described in the next paragraph and the last one is described in the paragraph that follows. We keep the model description succinct here, only describing the aspects most pertinent to our present analysis. 
The current model was developed from earlier simple climate models $(68,69)$ and produces an equivalent output with the one used in (23). The performance of the model (except for the economic module) was evaluated with those of other simple climate models under a set of common scenarios (70). The model is written by the General Algebraic Modeling System (GAMS) language.

The physical climate system is represented by an energy balance model coupled with a heat diffusion model $(22,71)$. Radiative forcing agents considered in the model include $\mathrm{CO}_{2}, \mathrm{CH}_{4}, \mathrm{~N}_{2} \mathrm{O}$, and $\mathrm{SF}_{6}$; 29 species of halocarbons, tropospheric, and stratospheric $\mathrm{O}_{3}$; and stratospheric water vapor. Aerosol forcing is separated by three terms: the direct effect of sulfate aerosols, the direct effect of black carbon and organic aerosols, and the indirect effects of all aerosols. The $\mathrm{CH}_{4}$ lifetime is influenced by $\mathrm{OH}, \mathrm{NO}_{\mathrm{x}}, \mathrm{CO}$, and VOC. Note that each forcing term is calculated separately without any gas aggregation using metrics such as GWP100. The global carbon cycle is provided by a box model: four boxes for the coupled atmosphere-ocean and another four for the land. Saturation of ocean $\mathrm{CO}_{2}$ uptake under rising atmospheric $\mathrm{CO}_{2}$ concentrations is modeled through the thermodynamic equilibrium of carbonate species in the ocean $(72,73)$. The $\mathrm{CO}_{2}$ fertilization of the land biosphere is parameterized by a commonly used $\beta$ factor. No climate-carbon feedbacks are assumed in our analysis; that is, carbon cycle processes are assumed to be insensitive to the temperature change. The equilibrium climate sensitivity is fixed at $3^{\circ} \mathrm{C}$, within the $1.5^{\circ}$ to $4.5^{\circ} \mathrm{C}$ range suggested by the IPCC AR5 (in the Thematic Focus Elements 6). Other uncertain parameters such as those related to aerosol forcing and $\mathrm{CO}_{2}$ fertilization are optimized on the basis of a Bayesian approach using historical observations such as global-mean temperature changes and atmospheric $\mathrm{CO}_{2}$ concentrations (74). The interdependencies among the parameter estimates are considered, including the one between the climate sensitivity and the aerosol forcing strength (75). The optimization is performed by using CONOPT3, a nonlinear optimization solver provided with GAMS.

The economy module is used to estimate the costs of mitigating $\mathrm{CO}_{2}$ (fossil fuel origin), $\mathrm{CH}_{4}$, and $\mathrm{N}_{2} \mathrm{O}$ emissions based on a first-order method using global MAC curves $(38,45)$ (fig. S2). The MAC curves are assumed time-invariant and given as a function of the abatement level (in percent) of the respective gas relative to an assumed baseline level [i.e., the International Institute for Applied Systems Analysis (IIASA) Greenhouse Gas Initiative (GGI) A2r baseline scenario (76)]. The fossil fuel $\mathrm{CO}_{2}$ MAC curve is based on the output of the Global Energy Transition (GET) model (45), which was simulated iteratively under different future trajectories of the carbon price. Although the carbon price for a given level of emission reductions should be timedependent, we use a mathematical function to approximate the data collected from 2060 to 2100 and apply it as the MAC function throughout the period in our analysis. Limitations associated with the fixed MAC curve approach are partially but imperfectly mitigated by the constraints on the temporal changes in the abatement level to account for the technological change and socioeconomic inertia associated with emission abatement. Namely, the rate of change in the abatement level (i.e., first derivative) is kept below $4 \%$ per year for all three gases, implying a limit for the technological change; furthermore, the rate of abatement change (i.e., second derivative) is below $0.4 \%$ per year, mimicking socioeconomic inertia. These firstand second-derivative constraints limit the extent of the MAC curves that can be used in the near term. The implication of these constraints is that, if the abatement starts in 2020, the abatement level can reach up to $20 \%$ in $2030,60 \%$ in 2040 , and $100 \%$ in 2050 (i.e., zero emissions from fossil fuel $\mathrm{CO}_{2}$ ). These constraints allow larger changes in the abatement level than those found in the 450 parts per million (ppm) $\mathrm{CO}_{2}$-equivalent scenarios in the AR5 database [supplementary figures 12 to 14 of (23)]. The maximum abatement levels for $\mathrm{CO}_{2}$ (fossil fuel origin), $\mathrm{CH}_{4}$, and $\mathrm{N}_{2} \mathrm{O}$ are assumed at 112, 70 , and $50 \%$, respectively. The abatement potential for $\mathrm{CO}_{2}$ can exceed $100 \%$ primarily because the IAM, on which our $\mathrm{CO}_{2} \mathrm{MAC}$ curve is based, considers bioenergy combined with carbon capture and storage as an option in the mitigation portfolio (45). Such deep mitigation could affect biodiversity and food security through landuse changes associated with large-scale negative emissions in a way that may not be acceptable in the real world (49-51), especially if large-scale low-diversity forest plantations and bioenergy crops coupled to capture and storage are the negative emissions technologies being preferentially adopted in the mid- to late century. Other political and governance constraints, which can be also important in the real world, are not considered in our model. Our approach is kept simple and works under the assumption that $\mathrm{CO}_{2}$ and non$\mathrm{CO}_{2}$ mitigation measures are interchangeable, which is partially true given the necessity to finance mitigation actions but may also break down for measures involving co-reduction of GHGs. Our MAC curve approach does not capture GHG abatement measures entailing net negative costs that have, however, not been implemented because of non-economic factors. The emissions of all other gases and pollutants including $\mathrm{CO}_{2}$ from land-use change are prescribed without cost calculations (i.e., GGI A2r 480 ppm $\mathrm{CO}_{2}$-equivalent stabilization). The discount rate is assumed at $4 \%$ by default. We analyze the pathway until 2200, going beyond the 2100 time frame commonly analyzed. The long time frame is required to capture overshoot pathways under which temperatures will not return to $2^{\circ} \mathrm{C}$ or lower during this century.

\section{Pathways and metric costs}

The stabilization and overshoot pathways were derived from the cost-effective calculation method described above. We allow the model to determine the abatement levels of three gases over time under the abatement constraints (i.e., first- and second-derivative constraints, as well as the upper limits of abatement levels) to arrive at a pathway that meets a policy objective while minimizing the global total costs of mitigation. Two temperature target levels $\left(2^{\circ}\right.$ and $\left.1.5^{\circ} \mathrm{C}\right)$ and three temperature pathway profiles [non-overshoot, medium overshoot (till 2100), and high overshoot (till 2150)] were considered. Temperature overshoot emerges as a consequence of how the temperature target is implemented: The target is assumed effective only after a certain point in time in the future.

It should be noted that the reference pathways against which the additional costs of using metrics were calculated are not identical to the illustrative pathways in Fig. 2. All metric cost calculations in our study did not use the abatement constraints, that is, the first- and second-derivative constraints, as well as the upper limits of abatement levels, which were used to derive the illustrative pathways. These constraints influence the metric cost calculations and, in some cases, make the pathway infeasible because they can be too restrictive when applied together with metrics. To maintain consistency, the abatement constraints were also not used in the reference pathways to derive the cost of metrics. However, the overall pathways and mitigation costs without the use of abatement constraints are not substantially different from those with the use of such constraints, 
except for cases with high overshoot. Another exception is the periods when the mitigation starts and when the target is met (table S2 and figs. S12 to S16). In such periods, particularly under the overshoot pathways, abatement levels can change drastically in the absence of the abatement constraints, requiring careful interpretation.

\section{Sensitivity analysis}

We consider the following three sources of uncertainty: equilibrium climate sensitivity, discount rate, and MAC curves. The equilibrium climate sensitivity is assumed to be $3^{\circ} \mathrm{C}$ by default, with sensitivity cases of $2^{\circ}$ and $4.5^{\circ} \mathrm{C}$. In comparison to the $1.5^{\circ}$ to $4.5^{\circ} \mathrm{C}$ range, the uncertainty in equilibrium climate sensitivity indicated by the IPCC AR5, our analysis did not consider climate sensitivity below $2^{\circ} \mathrm{C}$ as suggested by a previous study using ACC2 (74) and recent lines of evidences $(77,78)$. The discount rate is set at $4 \%$ by default and assumed at 2 and $6 \%$ in sensitivity cases, spanning a typical range considered in cost-effectiveness analyses (i.e., 5 to $6 \%$ in line with market interest rates), as well as low discount rates suggested by recent literature (79). The uncertainty in MAC curves is generally large, and a related study reports an uncertainty range of $\pm 50 \%$ in the MAC curves (55). We consider two cases changing the priority of $\mathrm{CO}_{2}$ and non- $\mathrm{CO}_{2}$ mitigation alternately: one case assuming a $50 \%$ higher $\mathrm{CO}_{2} \mathrm{MAC}$ curve and 50\% lower $\mathrm{CH}_{4}$ and $\mathrm{N}_{2} \mathrm{O}$ MAC curves and the opposite case assuming a 50\% lower $\mathrm{CO}_{2}$ MAC curve and 50\% higher $\mathrm{CH}_{4}$ and $\mathrm{N}_{2} \mathrm{O}$ MAC curves. Note that we vary the assumption on the $\mathrm{N}_{2} \mathrm{O}$ MAC curve for consistency, but this has little influence on the overall results. In the sensitivity analysis, we vary the assumptions on these uncertainties, just one by one from the default, and do not vary more than one assumption at a time owing to the computational burden, yielding a total of seven cases including the default case. A larger number of sources of uncertainty were considered in the historical inversion of the physical part of the model (74). However, in the metric cost analysis demanding more computational resource, we focus on the equilibrium climate sensitivity as the most important uncertain parameter in the physical earth system, while acknowledging that other parameters, including those related to climate-carbon cycle feedbacks, can also be important. Note that, with the climate sensitivity of $4.5^{\circ} \mathrm{C}$, the $2^{\circ} \mathrm{C}$ stabilization pathway and the $1.5^{\circ} \mathrm{C}$ medium overshoot pathway are not feasible with the abatement constraints put in place. As a result, these two pathways are not considered also in the metric cost analysis when the climate sensitivity is set at $4.5^{\circ} \mathrm{C}$, even though these pathways are feasible without the abatement constraints. The largest climate sensitivity that makes these target pathways feasible is $3.4^{\circ} \mathrm{C}$ in both cases.

In the analysis of best available metrics, we further consider the sensitivity of the assumed set of available metrics. The default set of time horizons considered for GWP and GTP are 100, 50, and 20 years. As a comparison, the IPCC AR5 lists the values of GWP20, GWP100, GTP20, GTP50, and GTP100 for a number of climate forcers in Table 8.A.1. AR5 also reports GWPs and GTPs with a time horizon of 100, 50, 20, and 10 years for a limited number of climate forcers in Table 8.SM.17. In contrast, the previous IPCC Assessment Reports up to AR4 present the values of GWPs with a time horizon of 500, 100, and 20 years (GTP values are only in AR5). We consider the following alternative sets of available time horizons for GWP and GTP: two time horizons (100 and 20 years) and six time horizons (500, 200, 100, 50, 20, and 10 years). In the sensitivity analysis, we choose a time horizon from two or six available time horizons, the $\mathrm{CH}_{4}$ GWP (or GTP) of which is closest to GCP at each point in time. The chosen time horizon is also used for $\mathrm{N}_{2} \mathrm{O}$ GWP (or GTP) as done in the default analysis. In this exercise, we refer to the AR5 metric values without inclusion of climate-carbon feedbacks for non- $\mathrm{CO}_{2}$ gases. Note that same metric values are assumed in the future period in our analysis. The IPCC metric values have changed over the assessment cycles due to several compounding and competing factors, including improvement in scientific understanding and changing background atmospheric conditions (Section 8.7.2.1 of the IPCC AR5). The metric values will probably be revised also in the future, but such changes are impossible to predict.

\section{Scenarios obtained from the IPCC SR15}

Data for the temperature pathways considered by SR15 were downloaded from the Integrated Assessment Modeling Consortium $1.5^{\circ} \mathrm{C}$ Scenario Explorer hosted by IIASA (48). The following five classes of pathways are considered in SR15: below $1.5^{\circ} \mathrm{C}, 1.5^{\circ} \mathrm{C}$-low OS, $1.5^{\circ} \mathrm{C}$-high OS, lower $2^{\circ} \mathrm{C}$, and higher $2^{\circ} \mathrm{C}$ (Table 2.1 of the IPCC SR15). Of 222 scenarios in the five classes, 92 temperature pathways are available from the Scenario Explorer website for download (accessed on 8 February 2019). Most of them are given for the period 2005-2100 with 5- or 10-year intervals. There are two temperature pathways indicating temperatures substantially higher than $2^{\circ} \mathrm{C}$ during this century (one peaking at $2.3^{\circ} \mathrm{C}$ in 2080 and the other at $2.66^{\circ} \mathrm{C}$ in 2090), which were removed from our analysis. Temperature data in SR15 use the 1850-1900 mean temperature as a reference. The $1850-1900$ mean temperature in our model is $0.0294^{\circ} \mathrm{C}$ based on the inverse calculation $(22,74)$. Thus, the SR15 temperature pathways shown in Fig. 2 are adjusted accordingly to account for the difference in the base temperature.

\section{SUPPLEMENTARY MATERIALS}

Supplementary material for this article is available at http://advances.sciencemag.org/cgi/ content/full/7/22/eabf9020/DC1

\section{REFERENCES AND NOTES}

1. IPCC, IPCC Expert Meeting on the Science of Alternative Metrics: Meeting Report, G.-K. Plattner, T. Stocker, P. Midgley, M. Tignor, Eds. Oslo, Norway, 18 to 20 March 2009 (University of Bern, 2009).

2. G. Myhre, D. Shindell, F. M. Bréon, W. Collins, J. Fuglestvedt, J. Huang, D. Koch, J. F. Lamarque, D. Lee, B. Mendoza, T. Nakajima, A. Robock, G. Stephens, T. Takemura, H. Zhang, Anthropogenic and natural radiative forcing, in Climate Change 2013: The Physical Science Basis. Contribution of Working Group I to the Fifth Assesment Report of the Intergovernmental Panel on Climate Change, T. F. Stocker, D. Qin, G. K. Plattner, M. M. B. Tignor, S. K. Allen, J. Boschung, A. Nauels, Y. Xia, V. Bex, P. M. Midgley, Eds. (Cambridge Univ. Press, 2013), chap. 8, pp.659-740.

3. D. A. Lashof, D. R. Ahuja, Relative contributions of greenhouse gas emissions to global warming. Nature 344, 529-531 (1990).

4. IPCC, Climate Change: The Intergovernmental Panel on Climate Change Scientific Assessment, J. T. Houghton, G. J. Jenkins, J. J. Ephraums, Eds. (Cambridge Univ. Press, 1990), 365 pp.

5. J. M. Reilly, K. R. Richards, Climate change damage and the trace gas index issue. Environ. Resource Econ. 3, 41-61 (1993).

6. T. M. L. Wigley, The Kyoto Protocol: $\mathrm{CO}_{2}, \mathrm{CH}_{4}$ and climate implications. Geophys. Res. Lett. 25, 2285-2288 (1998).

7. A. S. Manne, R. G. Richels, An alternative approach to establishing trade-offs among greenhouse gases. Nature 410, 675-677 (2001).

8. K. P. Shine, T. K. Berntsen, J. S. Fuglestvedt, R. B. Skeie, N. Stuber, Comparing the climate effect of emissions of short- and long-lived climate agents. Philos. Trans. A Math. Phys. Eng. Sci. 365, 1903-1914 (2007).

9. D. Shindell, G. Faluvegi, Climate response to regional radiative forcing during the twentieth century. Nat. Geosci. 2, 294-300 (2009).

10. K. Tanaka, B. C. O'Neill, D. Rokityanskiy, M. Obersteiner, R. Tol, Evaluating Global Warming Potentials with historical temperature. Clim. Change 96, 443-466 (2009).

11. G. P. Peters, B. Aamaas, T. Berntsen, J. S. Fuglestvedt, The integrated global temperature change potential (iGTP) and relationships between emission metrics. Environ. Res. Lett. 6 , 044021 (2011). 
12. D. J. A. Johansson, Economics- and physical-based metrics for comparing greenhouse gases. Clim. Change 110, 123-141 (2012).

13. E. Sterner, D. J. A. Johansson, C. Azar, Emission metrics and sea level rise. Clim. Change 127, 335-351 (2014).

14. K. P. Shine, R. P. Allan, W. J. Collins, J. S. Fuglestvedt, Metrics for linking emissions of gases and aerosols to global precipitation changes. Earth Syst. Dynam. 6, 525-540 (2015).

15. M. R. Allen, J. S. Fuglestvedt, K. P. Shine, A. Reisinger, R. T. Pierrehumbert, P. M. Forster New use of global warming potentials to compare cumulative and short-lived climate pollutants. Nat. Clim. Chang. 6, 773-776 (2016).

16. J. S. Fuglestvedt, T. K. Berntsen, O. Godal, R. Sausen, K. P. Shine, T. Skodvin, Metrics of climate change: Assessing radiative forcing and emission indices. Clim. Change 58, 267-331 (2003).

17. K. Tanaka, G. P. Peters, J. S. Fuglestvedt, Policy update: Multicomponent climate policy: Why do emission metrics matter? Carbon Manag. 1, 191-197 (2010).

18. M. Cain, J. Lynch, M. R. Allen, J. S. Fuglestvedt, D. J. Frame, A. H. Macey, Improved calculation of warming-equivalent emissions for short-lived climate pollutants. NPJ Clim. Atmos. Sci. 2, 29 (2019).

19. C.-F. Schleussner, A. Nauels, M. Schaeffer, W. Hare, J. Rogelj, Inconsistencies when applying novel metrics for emissions accounting to the Paris agreement. Environ. Res. Lett. 14, 124055 (2019).

20. UNFCCC, "Report of the Conference of the Parties serving as the meeting of the Parties to the Paris Agreement on the third part of its first session, held in Katowice from 2 to 15 December 2018. Addendum 2. Part two: Action taken by the Conference of the Parties serving as the meeting of the Parties to the Paris Agreement" (FCCC/PA/CMA/2018/3/ Add.2 2019).

21. UNFCCC, "United Nations Framework Convention on Climate Change" (FCC/INFORMAL/84/ Rev.1; 1992).

22. K. Tanaka, E. Kriegler, T. Bruckner, G. Hooss, W. Knorr, T. Raddatz, Aggregated Carbon Cycle, Atmospheric Chemistry, and Climate Model (ACC2)—Description of the forward and inverse modes, in Reports on Earth System Science (Max Planck Institute for Meteorology, 2007), vol. 40.

23. K. Tanaka, B. C. O'Neill, The Paris Agreement zero-emissions goal is not always consistent with the $1.5^{\circ} \mathrm{C}$ and $2^{\circ} \mathrm{C}$ temperature targets. Nat. Clim. Chang. 8, 319-324 (2018).

24. IPCC, "Global warming of $1.5^{\circ} \mathrm{C}$ ", IPCC Special Report (2018).

25. A. Reisinger, P. Havlik, K. Riahi, O. van Vliet, M. Obersteiner, M. Herrero, Implications of alternative metrics for global mitigation costs and greenhouse gas emissions from agriculture. Clim. Change 117, 677-690 (2013).

26. J. Strefler, G. Luderer, T. Aboumahboub, E. Kriegler, Economic impacts of alternative greenhouse gas emission metrics: A model-based assessment. Clim. Change 125 319-331 (2014).

27. M. van den Berg, A. F. Hof, J. van Vliet, D. P. van Vuuren, Impact of the choice of emission metric on greenhouse gas abatement and costs. Environ. Res. Lett. 10, 024001 (2015).

28. M. J. H. M. Harmsen, M. van den Berg, V. Krey, G. Luderer, A. Marcucci, J. Strefler, D. P. van Vuuren, How climate metrics affect global mitigation strategies and costs: A multi-model study. Clim. Change 136, 203-216 (2016).

29. Z. Hausfather, G. P. Peters, Emissions-The 'business as usual' story is misleading. Nature 557, 618-620 (2020).

30. W. Cornwall, Five years in, Paris pact still a work in progress. Science 370, 1390-1390 (2020).

31. O. Boucher, V. Bellassen, H. Benveniste, P. Ciais, P. Criqui, C. Guivarch, H. le Treut S. Mathy, R. Séférian, Opinion: In the wake of Paris Agreement, scientists must embrace new directions for climate change research. Proc. Natl. Acad. Sci. U.S.A. 113, 7287-7290 (2016).

32. N. Höhne, M. den Elzen, J. Rogelj, B. Metz, T. Fransen, T. Kuramochi, A. Olhoff, J. Alcamo, H. Winkler, S. Fu, M. Schaeffer, R. Schaeffer, G. P. Peters, S. Maxwell, N. K. Dubash, Emissions: World has four times the work or one-third of the time. Nature 579, 25-28 (2020)

33. Z. Liu, P. Ciais, Z. Deng, R. Lei, S. J. Davis, S. Feng, B. Zheng, D. Cui, X. Dou, B. Zhu, R. Guo, P. Ke, T. Sun, C. Lu, P. He, Y. Wang, X. Yue, Y. Wang, Y. Lei, H. Zhou, Z. Cai, Y. Wu, R. Guo, T. Han, J. Xue, O. Boucher, E. Boucher, F. Chevallier, K. Tanaka, Y. Wei, H. Zhong, C. Kang, N. Zhang, B. Chen, F. Xi, M. Liu, F. M. Bréon, Y. Lu, Q. Zhang, D. Guan, P. Gong, D. M. Kammen, K. He, H. J. Schellnhuber, Near-real-time monitoring of global $\mathrm{CO}_{2}$ emissions reveals the effects of the COVID-19 pandemic. Nat. Commun. 11, 5172 (2020).

34. C. Hepburn, B. O'Callaghan, N. Stern, J. Stiglitz, D. Zenghelis, Will COVID-19 fiscal recovery packages accelerate or retard progress on climate change? Oxf. Rev. Econ. Policy 36, S359-S381 (2020).

35. B. C. O'Neill, M. Oppenheimer, Climate change impacts are sensitive to the concentration stabilization path. Proc. Natl. Acad. Sci. U.S.A. 101, 16411-16416 (2004).

36. M. G. J. den Elzen, D. P. van Vuuren, Peaking profiles for achieving long-term temperature targets with more likelihood at lower costs. Proc. Natl. Acad. Sci. U.S.A. 104, 17931-17936 (2007).
37. O. Geden, A. Löschel, Define limits for temperature overshoot targets. Nat. Geosci. 10 881-882 (2017).

38. K. Tanaka, D. J. A. Johansson, B. C. O'Neill, J. S. Fuglestvedt, Emission metrics under the $2{ }^{\circ} \mathrm{C}$ climate stabilization target. Clim. Change 117, 933-941 (2013).

39. J. Fuglestvedt, J. Rogelj, R. J. Millar, M. Allen, O. Boucher, M. Cain, P. M. Forster, E. Kriegler, D. Shindell, Implications of possible interpretations of "greenhouse gas balance" in the Paris Agreement. Philos. Trans. A Math. Phys. Eng. Sci. 376, 20160445 (2018)

40. UNFCCC, "Common metrics," 2020; https://unfccc.int/process-and-meetings/ transparency-and-reporting/methods-for-climate-change-transparency/commonmetrics.

41. UNFCCC, "Provisional agenda and annotations. Note by the Executive Secretary" (FCCC SBSTA/2020/1; English version, 2020)

42. UNFCCC, SBSTA 51 agenda item 10(d) Common metrics to calculate the carbon dioxide equivalence of greenhouse gases (FCCC/SBSTA/2019/L.X/Add.1; draft, English version, 2020).

43. K. Shine, B. Collins, M. Allen, J. Lynch, M. Cain, D. Frame, A. Macey, K. Tanaka, Voluntary submission for SBSTA 52 Agenda Item 8(b) Methodological issues under the convention: Common metrics to calculate equivalence of greenhouse gases (2020); https://www4. unfccc.int/sites/SubmissionsStaging/Documents/202005041045---SBSTA APRIL2020. pdf

44. R. S. J. Tol, T. K. Berntsen, B. C. O'Neill, J. S. Fuglestvedt, K. P. Shine, A unifying framework for metrics for aggregating the climate effect of different emissions. Environ. Res. Lett. 7, 044006 (2012).

45. C. Azar, D. J. A. Johansson, N. Mattsson, Meeting global temperature targets-The role of bioenergy with carbon capture and storage. Environ. Res. Lett. 8, 034004 (2013).

46. M. den Elzen, M. Meinshausen, D. van Vuuren, Multi-gas emission envelopes to meet greenhouse gas concentration targets: Costs versus certainty of limiting temperature increase. Glob. Environ. Chang. 17, 260-280 (2007).

47. F. Kesicki, N. Strachan, Marginal abatement cost (MAC) curves: Confronting theory and practice. Environ. Sci. Policy 14, 1195-1204 (2011).

48. D. Huppmann, J. Rogelj, E. Kriegler, V. Krey, K. Riahi, A new scenario resource for integrated $1.5^{\circ} \mathrm{C}$ research. Nat. Clim. Chang. 8, 1027-1030 (2018).

49. P. Smith, S. J. Davis, F. Creutzig, S. Fuss, J. Minx, B. Gabrielle, E. Kato, R. B. Jackson A. Cowie, E. Kriegler, D. P. van Vuuren, J. Rogelj, P. Ciais, J. Milne, J. G. Canadell, D. McCollum, G. Peters, R. Andrew, V. Krey, G. Shrestha, P. Friedlingstein, T. Gasser, A. Grübler, W. K. Heidug, M. Jonas, C. D. Jones, F. Kraxner, E. Littleton, J. Lowe, J. R. Moreira, N. Nakicenovic, M. Obersteiner, A. Patwardhan, M. Rogner, E. Rubin A. Sharifi, A. Torvanger, Y. Yamagata, J. Edmonds, C. Yongsung, Biophysical and economic limits to negative $\mathrm{CO}_{2}$ emissions. Nat. Clim. Chang. 6, 42-50 (2016).

50. National Academies of Sciences Engineering Medicine, Negative Emissions Technologies and Reliable Sequestration: A Research Agenda (The National Academies Press, 2019), $510 \mathrm{pp}$.

51. IPCC, "Climate Change and Land: An IPCC special report on climate change, desertification, land degradation, sustainable land management, food security, and greenhouse gas fluxes in terrestrial ecosystems" (2019); https://www.ipcc.ch/srccl/.

52. F. Joos, R. Roth, J. S. Fuglestvedt, G. P. Peters, I. G. Enting, W. von Bloh, V. Brovkin E. J. Burke, M. Eby, N. R. Edwards, T. Friedrich, T. L. Frölicher, P. R. Halloran, P. B. Holden, C. Jones, T. Kleinen, F. T. Mackenzie, K. Matsumoto, M. Meinshausen, G. K. Plattner, A. Reisinger, J. Segschneider, G. Shaffer, M. Steinacher, K. Strassmann, K. Tanaka, A. Timmermann, A. J. Weaver, Carbon dioxide and climate impulse response functions for the computation of greenhouse gas metrics: A multi-model analysis. Atmos. Chem. Phys. 13, 2793-2825 (2013).

53. B. C. O'Neill, Economics, natural science, and the costs of Global Warming Potentials. Clim. Change 58, 251-260 (2003).

54. A. Aaheim, J. S. Fuglestvedt, O. Godal, Costs savings of a flexible multi-gas climate policy. Energy J. 27, 485-502 (2006)

55. D. Johansson, U. Persson, C. Azar, The cost of using Global Warming Potentials: Analysing the trade off between $\mathrm{CO}_{2}, \mathrm{CH}_{4}$ and $\mathrm{N}_{2} \mathrm{O}$. Clim. Change 77, 291-309 (2006).

56. R. W. Howarth, Methane emissions from fossil fuels: Exploring recent changes in greenhouse-gas reporting requirements for the State of New York. J. Integr. Environ. SCi. 17, 69-81 (2020)

57. A. Reisinger, M. Meinshausen, M. Manning, G. Bodeker, Uncertainties of global warming metrics: $\mathrm{CO}_{2}$ and $\mathrm{CH}_{4}$. Geophys. Res. Lett. 37, L14707 (2010).

58. F. Cherubini, J. Fuglestvedt, T. Gasser, A. Reisinger, O. Cavalett, M. A. J. Huijbregts, D. J. A. Johansson, S. V. Jørgensen, M. Raugei, G. Schivley, A. H. Strømman, K. Tanaka, A. Levasseur, Bridging the gap between impact assessment methods and climate science. Environ. Sci. Policy 64, 129-140 (2016).

59. F. Cherubini, K. Tanaka, Amending the inadequacy of a single indicator for climate impact analyses. Environ. Sci. Technol. 50, 12530-12531 (2016).

60. A. Levasseur, O. Cavalett, J. S. Fuglestvedt, T. Gasser, D. J. A. Johansson, S. V. Jørgensen, M. Raugei, A. Reisinger, G. Schivley, A. Strømman, K. Tanaka, F. Cherubini, Enhancing life 
cycle impact assessment from climate science: Review of recent findings and recommendations for application to LCA. Ecol. Indic. 71, 163-174 (2016).

61. A. Reisinger, S. F. Ledgard, S. J. Falconer, Sensitivity of the carbon footprint of New Zealand milk to greenhouse gas metrics. Ecol. Indic. 81, 74-82 (2017).

62. K. Tanaka, O. Cavalett, W. J. Collins, F. Cherubini, Asserting the climate benefits of the coal-to-gas shift across temporal and spatial scales. Nat. Clim. Chang. 9, 389-396 (2019).

63. K. Tibrewal, C. Venkataraman, Climate co-benefits of air quality and clean energy policy in India. Nat. Sustain. 4, 305-313 (2021).

64. P. Ciais, C. Sabine, G. Bala, L. Bopp, V. Brovkin, J. Canadell, A. Chhabra, R. DeFries, J. Galloway, M. Heimann, C. Jones, C. Le Quéré, R. B. Myneni, S. Piao, P. Thornton, Carbon and other biogeochemical cycles, in Climate Change 2013: The Physical Science Basis. Contribution of Working Group I to the Fifth Assessment Report of the Intergovernmental Panel on Climate Change, T. F. Stocker, D. Qin, G.-K. Plattner, M. Tignor, S. K. Allen, J. Boschung, A. Nauels, Y. Xia, V. Bex, P. M. Midgley, Eds. (Cambridge Univ. Press, 2013), chap. 6, pp. 465-570.

65. W. J. Collins, D. J. Frame, J. S. Fuglestvedt, K. P. Shine, Stable climate metrics for emissions of short and long-lived species-Combining steps and pulses. Environ. Res. Lett. 15 024018 (2020).

66. J. Lynch, M. Cain, R. Pierrehumbert, M. Allen, Demonstrating GWP*: A means of reporting warming-equivalent emissions that captures the contrasting impacts of short- and longlived climate pollutants. Environ. Res. Lett. 15, 044023 (2020).

67. P. Leiby, J. Rubin, Intertemporal permit trading for the control of greenhouse gas emissions. Environ. Resource Econ. 19, 229-256 (2001).

68. G. Hooss, R. Voss, K. Hasselmann, E. Maier-Reimer, F. Joos, A nonlinear impulse response model of the coupled carbon cycle-climate system (NICCS). Climate Dynam. 18, 189-202 (2001).

69. T. Bruckner, G. Hooss, H.-M. Füssel, K. Hasselmann, Climate system modeling in the framework of the Tolerable Windows Approach: The ICLIPS climate model. Clim. Change 56, 119-137 (2003).

70. Z. R. J. Nicholls, M. Meinshausen, J. Lewis, R. Gieseke, D. Dommenget, K. Dorheim C. S. Fan, J. S. Fuglestvedt, T. Gasser, U. Golüke, P. Goodwin, C. Hartin, A. P. Hope, E. Kriegler, N. J. Leach, D. Marchegiani, L. A. McBride, Y. Quilcaille, J. Rogelj, R. J. Salawitch, B. H. Samset, M. Sandstad, A. N. Shiklomanov, R. B. Skeie, C. J. Smith, S. Smith, K. Tanaka, J. Tsutsui, Z. Xie, Reduced Complexity Model Intercomparison Project Phase 1: Introduction and evaluation of global-mean temperature response. Geosci. Model Dev. 13, 5175-5190 (2020).

71. E. Kriegler, Universität Potsdam, Germany (2005).

72. F. T. Mackenzie, A. Lerman, Carbon in the Geobiosphere: Earth's Outer Shell (Springer, 2006), $423 \mathrm{pp}$.

73. K. Kvale, K. Zickfeld, T. Bruckner, K. J. Meissner, K. Tanaka, A. J. Weaver, Carbon dioxide emission pathways avoiding dangerous ocean impacts. Weather Clim. Soc. 4, 212-229 (2012).

74. K. Tanaka, T. Raddatz, B. C. O'Neill, C. H. Reick, Insufficient forcing uncertainty underestimates the risk of high climate sensitivity. Geophys. Res. Lett. 36, L16709 (2009).

75. K. Tanaka, T. Raddatz, Correlation between climate sensitivity and aerosol forcing and its implication for the "climate trap". Clim. Change 109, 815-825 (2011).
76. K. Riahi, A. Grübler, N. Nakicenovic, Scenarios of long-term socio-economic and environmental development under climate stabilization. Technol. Forecast. Soc Change 74, 887-935 (2007).

77. R. Knutti, M. A. A. Rugenstein, G. C. Hegerl, Beyond equilibrium climate sensitivity. Nat. Geosci. 10, 727-736 (2017).

78. S. C. Sherwood, M. J. Webb, J. D. Annan, K. C. Armour, P. M. Forster, J. C. Hargreaves, G. Hegerl, S. A. Klein, K. D. Marvel, E. J. Rohling, M. Watanabe, T. Andrews, P. Braconnot, C. S. Bretherton, G. L. Foster, Z. Hausfather, A. S. von der Heydt, R. Knutti, T. Mauritsen, J. R. Norris, C. Proistosescu, M. Rugenstein, G. A. Schmidt, K. B. Tokarska, M. D. Zelinka, An assessment of Earth's climate sensitivity using multiple lines of evidence. Rev. Geophys. 58, e2019RG000678 (2020).

79. J. Emmerling, L. Drouet, K.-I. van der Wijst, D. van Vuuren, V. Bosetti, M. Tavoni, The role of the discount rate for emission pathways and negative emissions. Environ. Res. Lett. 14, 104008 (2019).

80. T. Gasser, G. P. Peters, J. S. Fuglestvedt, W. J. Collins, D. T. Shindell, P. Ciais, Accounting for the climate-carbon feedback in emission metrics. Earth Syst. Dynam. 8, 235-253 (2017).

Acknowledgments: We are grateful for comments and suggestions from S. Emori, J. Fuglestvedt, B. O'Neill, H. Shiogama, K. Takahashi, K. Tanaka, J. Tsutsui, and T. Yokohata, which were useful for this study. Funding: This work benefited from State assistance managed by the National Research Agency in France under the Programme d'Investissements d'Avenir under the reference ANR-19-MPGA-0008. K.T. was supported by the Make Our Planet Great Again (MOPGA) Short-Stay grant in France ( $\mathrm{N}^{\circ}$ dossier: 927201A) and the Environment Research and Technology Development Fund (JPMEERF20202002) of the Environmental Restoration and Conservation Agency (Japan). O.B. acknowledges support from the Ministère de la transition écologique et solidaire (MTES) of France through the "Convention relative à l'attribution d'un appui financier au bénéfice des services climatiques." P.C. acknowledges support from the ESA Climate Change Initiative Project RECCAP-2 CN 3 ESA Co. 400012300220 SSR064. P.C. acknowledges support from the ANR CLAND Convergence Institute 16-CONV-0003. D.J.A.J. acknowledges financial support from Vinnova (grant no. 2019-03233). Author contributions: K.T. and O.B. conceived this study. K.T. led the study. K.T., O.B., P.C., and D.J.A.J. designed the experiment. K.T. performed the analysis. K.T., O.B., P.C., D.J.A.J., and J.M. analyzed the results. K.T. drafted the manuscript, with contributions from all coauthors. Competing interests: J.M. was previously employed by the Swedish Government. The views expressed in this paper are those of the authors and do not reflect the official position of the Swedish Government. The other authors declare that they have no competing interests. Data and materials availability: All data needed to evaluate the conclusions in the paper are present in the paper and/or the Supplementary Materials and are available on Zenodo with doi.org/10.5281/ zenodo.4630539.

Submitted 26 November 2020

Accepted 9 April 2021

Published 28 May 2021

$10.1126 /$ sciadv.abf9020

Citation: K. Tanaka, O. Boucher, P. Ciais, D. J. A. Johansson, J. Morfeldt, Cost-effective implementation of the Paris Agreement using flexible greenhouse gas metrics. Sci. Adv. 7, eabf9020 (2021). 


\section{ScienceAdvances}

Cost-effective implementation of the Paris Agreement using flexible greenhouse gas metrics

Katsumasa Tanaka, Olivier Boucher, Philippe Ciais, Daniel J. A. Johansson and Johannes Morfeldt

Sci Adv 7 (22), eabf9020.

DOI: $10.1126 /$ sciadv.abf9020

ARTICLE TOOLS

SUPPLEMENTARY

MATERIALS

REFERENCES

PERMISSIONS http://advances.sciencemag.org/content/7/22/eabf9020

http://advances.sciencemag.org/content/suppl/2021/05/24/7.22.eabf9020.DC1

This article cites 64 articles, 4 of which you can access for free http://advances.sciencemag.org/content/7/22/eabf9020\#BIBL

http://www.sciencemag.org/help/reprints-and-permissions

Science Advances (ISSN 2375-2548) is published by the American Association for the Advancement of Science, 1200 New York Avenue NW, Washington, DC 20005. The title Science Advances is a registered trademark of AAAS.

Copyright (C) 2021 The Authors, some rights reserved; exclusive licensee American Association for the Advancement of Science. No claim to original U.S. Government Works. Distributed under a Creative Commons Attribution NonCommercial License 4.0 (CC BY-NC). 